DE DE GRUYTER

OPEN

.

BULGARIAN ACADEMY OF SCIENCES

CYBERNETICS AND INFORMATION TECHNOLOGIES • Volume 15, No 6

Special Issue on Logistics, Informatics and Service Science

Sofia • 2015

Print ISSN: 1311-9702; Online ISSN: 1314-4081

DOI: 10.1515/cait-2015-0078

\title{
Simulation on Stern-Rudder Independent Control for Submarine Motion in a Vertical Plane
}

\author{
Xiong Ying, Hu Jun Jie \\ South-Central University for Nationalities, Wuhan, 430074 China \\ Email: 304074461@qq.com
}

Abstract: To independently control the depth and trim of the submarine, a fuzzy control method on stern-rudder is proposed, and the advantage of a single sternrudder in low noise control is elaborated. Taking into account the character of the single stern-rudder, a fuzzy controller is designed. The simulation results have shown that the algorithm has very good control precision, which decreases the rudder and radiated noise greatly.

Keywords: Submarine, motion in a vertical plane, fuzzy control.

\section{Introduction}

The submarine space motion in water can be decomposed into two plane motions, namely the weak maneuvering of submarines moving in the horizontal plane with ships' movement above water as a main research direction to maintain and change, which does not involve depth changes; and a submarine in vertical plane movement, which mainly studies the pitch and depth keeping and changes without involving heading changes. The vertical plane movement is an important aspect which is different from a ship on the surface, as well as an important guarantee for the submarine to make full use of its tactical performance. Therefore, it is very important to study the law of vertical surface movement of the submarine [1-5].

As we all know, the reduction of the submarine noise can efficiently increase the detection range of a sonar, and using double rudder submarine noise controlling 
has greater effect than using single stern rudder control. Since the sonar is located in the submarine's bow, in low noise sailing conditions, keeping zero for a shell around the rudder can reduce the disturbance to the surrounding fluid of the peripheral rudder hull, which eliminates splashing of the hydrodynamic noise of rudder movement. At the same time around the shell actuator, a closed state mechanical noise is also found, so the pipeline of the hydraulic shock noise and the component friction noise are removed. Therefore, single stern rudder control can achieve a local noise reduction effect, thereby increasing the detection range of the sonar to a certain extent.

In addition, considering the submarine maneuvering safety, a general submarine stern rudder is in the wake of the propeller and rudder stern in the propeller, so the rudder effect is significantly enhanced. Besides, the submarine stern rudder is far away from the centre of confining the rudder hull of the submarine, so compared with the peripheral rudder hull, the advantage of the stern rudder is the arm. Usually the ratio of the length of the stern rudder arm to the confining shell rudder arm is about 1:3, due to the three times longer length of the stern rudder compared to the confining rudder hull in the same area. The strong control ability of the stern rudder leads to easier trim or restores the trim. In addition, the stern rudder is equipped with larger area and exhibition side than the sailplane, so it can provide more lift power. Thus, the stern rudder control ability is stronger than the enclosed shell rudder. This is the reason for using a single stern rudder control rather than a single round shell rudder control.

To sum up, the single stern rudder control has great advantage in submarine low noise operation; it can reduce to some extent the submarine self-noise and radiation noise and improve the submarine stealth and combat performance. This paper adopts the scheme of single stern rudder control to further reduce the submarine noise.

\section{The design of a fuzzy control scheme}

In the case of single submarine stern rudder control, the pitch and depth control of a submarine are taken into account. In the design of a controller there are four control inputs: depth deviation, deviation change rate, trim of the deviation and its change rate, which is likely to give rise to a complex fuzzy controller structure, large rule base, affecting the solution efficiency of fuzzy nature. When the submarine is in depth, generally the first thing is to control the vertical tilt, when the vertical tilt is in command, and then according to the current depth of the deviation to control the depth of the specified depth. Therefore, this paper will use two fuzzy controllers, a controller manipulating the stern rudder to control the pitch, and another controller to control the depth through stern rudder manipulation. At the starting stage of the depth motor, when the directive trim is reached, the control is switched to the depth controller, and through the depth bias the depth control is executed to a further instruction. Since the submarine has the right to make up a torque, at the same time the torque will be pulled to a zero longitudinal tilt. Its structure is shown in Fig. 1. 


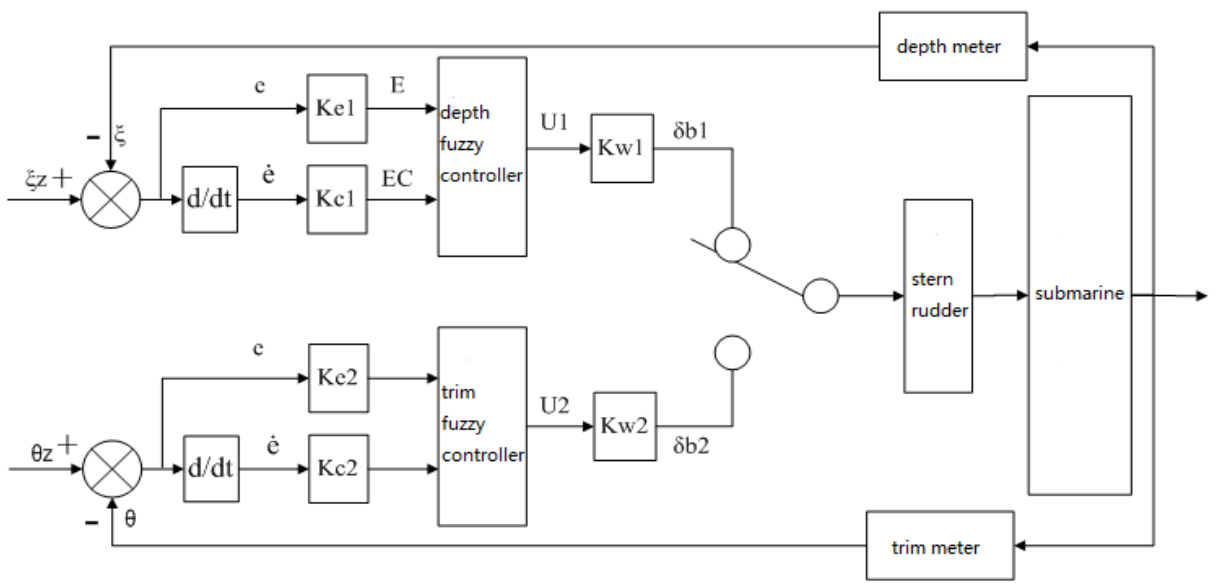

Fig. 1. Single stern rudder fuzzy control structure

\section{The depth design of a fuzzy controller}

The depth fuzzy controller will choose a two-dimensional fuzzy controller [6-11]. The fuzzy controller has two controller inputs, the depth deviation $\Delta \xi=\xi_{z}-\xi$, and depth deviation change rate $\gamma=d \Delta \xi / d t$. The depth deviation rate of the change is a differential signal, but the depth of the submarine deviation change rate cannot be directly obtained by the sensor. And as the depth is quantified by a deviation differential digital, we also need a differentiator to get the micro components. In traditional conditioning theory, the scholars have adopted the method of direct differential to get the depth and trim of the first-order micro component, which is also one of the commonly used processing methods. But with the classic differentiator, differential signals contaminated by random signal amplifier noise pollution will occur and cause the burr and jitters of the differential signal. Through mathematical deduction, we have obtained that the output signal $y(t)$ is composed of a differential signal and magnified $1 / T$ noise signal of time.

The time constant $T$ is very small, so the noise amplification is very serious, which sometimes can completely submerge the differential signal $\dot{v}(t)$, hence the classical differential link severely amplifies the effect of noise. Therefore, in the process of differential treatment we need to avoid the state, in which the variable differential is producing other variables. For these reasons, this paper will use a new type of a tracking differentiator. The steepest nonlinear tracking differentiator can overcome the noise amplification effect of second and higher order differential link. The steepest nonlinear tracking differentiator algorithm formula can be presented as follows:

$$
\left.\begin{array}{l}
\dot{x}_{1}=x_{2} \\
\dot{x}_{2}=\varepsilon
\end{array}\right\}
$$


The output equation is $y=\dot{u}=x$, including $\varepsilon=\mathrm{fthan}\left(x_{1}-u, x_{2}, r, h_{0}\right)$. In the formula $u$ denotes the input signal, the depth is $\xi ; \dot{u}$ - the depth of the tracking differentiator output differential signal $\dot{\xi}$, and

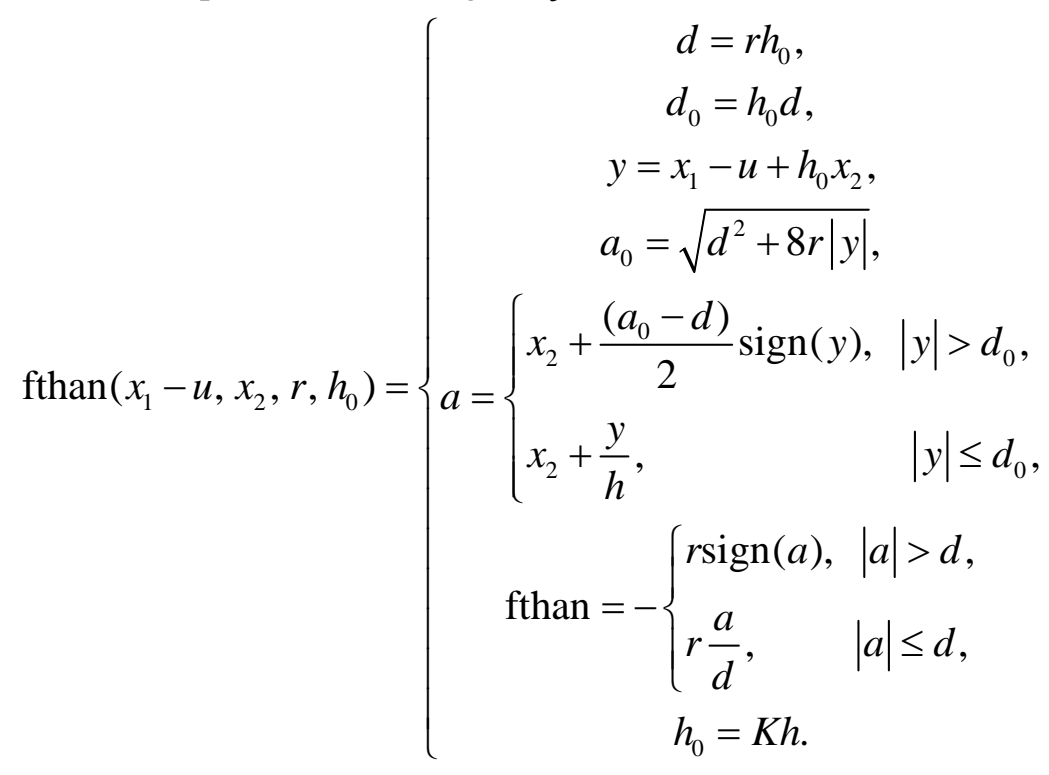

The depth of the signal as an input, the classic differentiator and differential signal of the steepest nonlinear tracking differentiator can be obtained respectively.

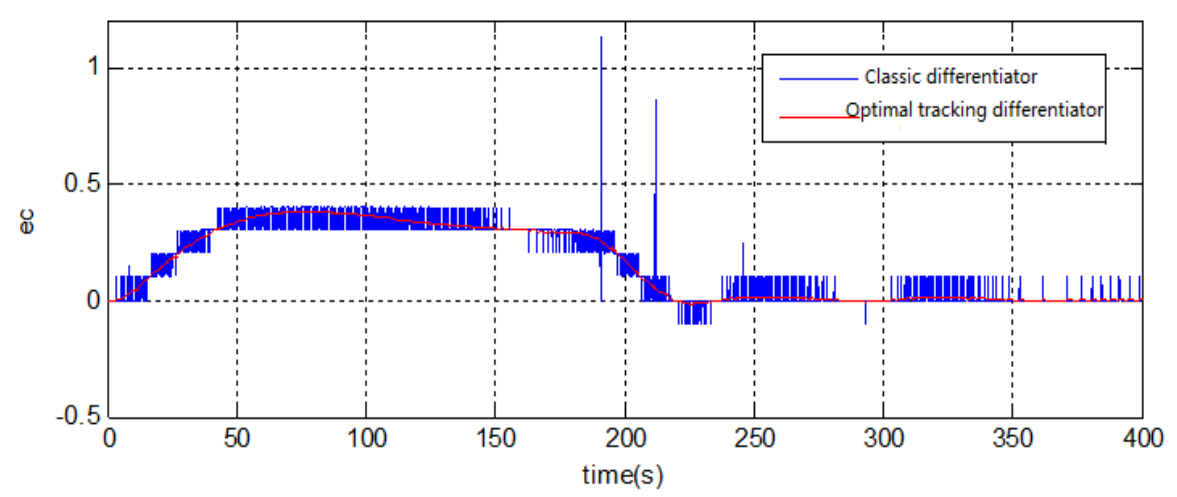

Fig. 2. Two kinds of differentiator signal comparison

As it can be seen from Fig. 2, the classical differentiator of the differential signal tremble is obvious and even distorting. The steepest nonlinear tracking differentiator out of the differential signal is very smooth, as well as the design of trimming and heading of the controller, so we can use the steepest nonlinear tracking differential device to track the longitudinal tilt and heading of the differential signal. Thus, we can improve the control effect of the fuzzy controller to a large extent. 


\subsection{Theory and basic theory of domains}

The depth of the deviation theory domain for $\Delta \xi=\xi_{z}-\xi$ to $[10,10]$, the depth deviation rate is $\gamma=d \Delta \xi / d t$, the universe is [2, 2] , and the control theory of stern rudder angle domain $\delta_{\mathrm{s}}[6,6]$. According to the actual situation, choose the depth deviation control system of the basic theory of the domain as $[100,100]$, the depth deviation rate of the basic theory of domain [2, 2], and the stern rudder angle of the basic theory of the domain [30, 30].

\subsection{Quantization factor and scaling factor}

In deterministic theory and basic theory of domains, the quantization factor and the scaling factor can be determined as follows:

The depth of the deviation quantization factor $K_{\mathrm{e} 2}=10 / 100=0.1$.

The depth of the deviation change rate quantization factor $K_{\mathrm{ec} 2}=0.5$.

The output of the scaling factor $K_{\mathrm{w} 2}=30 / 6=5$.

\subsection{Fuzzy language variables and determination of the membership function}

The input and output language variables of the fuzzy controller is set to five, respectively $\{(\mathrm{NB}),(\mathrm{NS}),(\mathrm{ZE}),(\mathrm{PS}),(\mathrm{PB})\}$. According to the fuzzy language, the variables can be obtained from depth deviation, deviation rate and stern rudder angle. The membership function of the fuzzy subset is shown in Figs 3, 4 and 5.

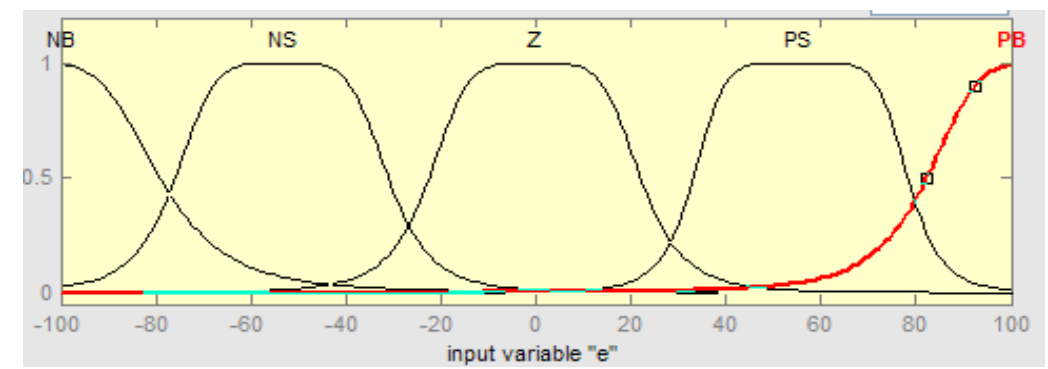

Fig. 3. Membership function of the depth of the deviation $\Delta \xi$

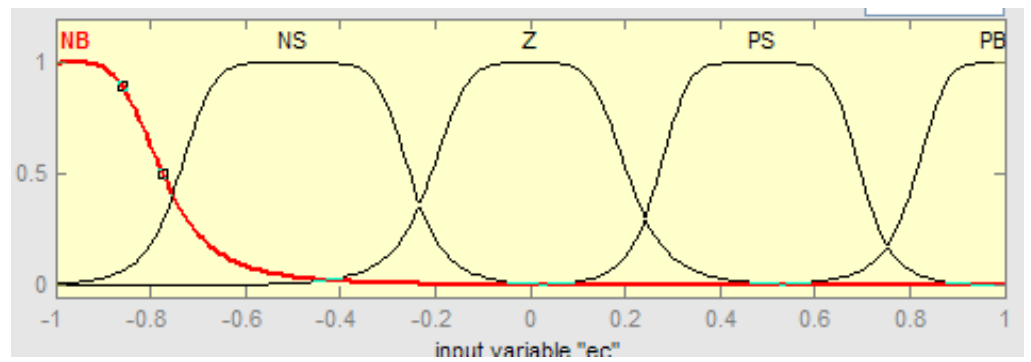

Fig. 4. Membership function of the depth of the deviation change rate $\gamma$ 


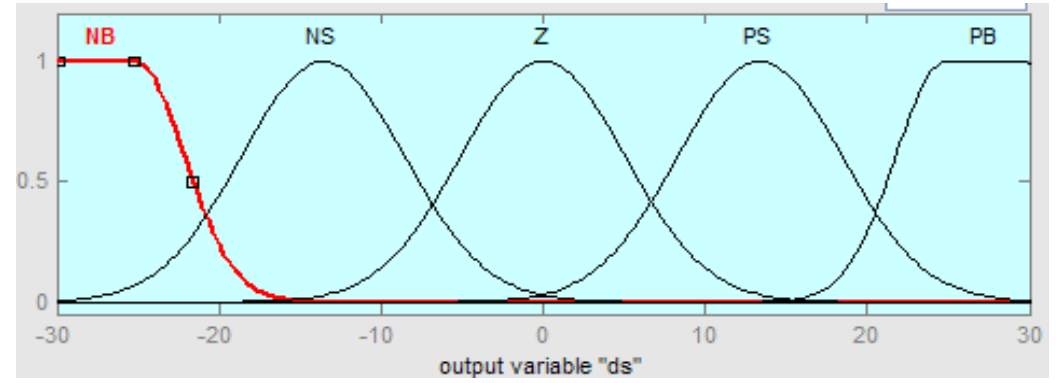

Fig. 5. Membership function of the stern rudder angle $\delta_{\mathrm{s}}$

\subsection{Determination of the fuzzy rules}

To obtain the fuzzy rules of the depth of the controller requires submarine control engineering theory knowledge, as well as expert's advice and practical operational experience from the older generation. For the depth of a motor during the submarine manipulation, the steering personnel experience is very important. In general, the design of the fuzzy rules will be based on the actual operation process. In the process of the depth of the motor, we can refer to the step response of a typical fuzzy rule being specified.

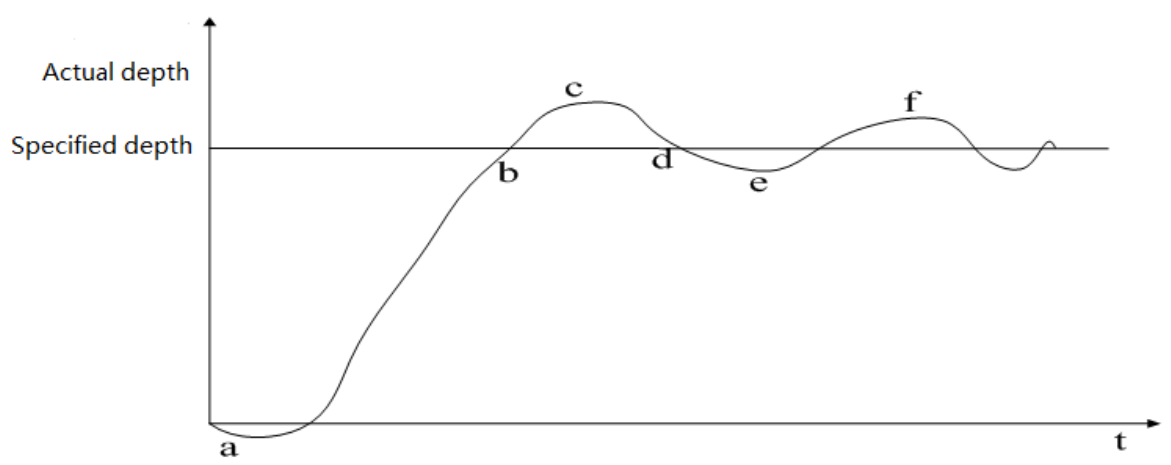

Fig. 6. Depth of the submarine maneuver control process of a typical step response

Fig. 6 describes the typical step response of the depth of submarine maneuvers. At the beginning, near point a, the depth of the deviation $\Delta \xi$ is very large, and the depth of the deviation rate of change $\gamma$ is very small. In order to eliminate the depth deviation at this moment, we need a large rudder angle signal in fast variable depth to minimize the deviation submarines. Hence, near to the point a, the rule is: if the deviation $\Delta \xi$ is PB and depth $\gamma$ is ZE or NS, the stern rudder angle $\delta_{\mathrm{s}}$ is $\mathrm{NB}$ (negative).

Near point b in Fig. 6, the depth of the deviation $\Delta \xi$ is very small, and the deviation change rate $\gamma$ is large. To prevent the system overshoot and oscillation at this moment, we need a control signal of PS in order to avoid excessive overshoot 
actual depth. So near to the point b, the rule is: if the depth of the deviation $\Delta \xi$ is NS or ZE and $\gamma$ is NB, the stern rudder angle $\delta_{\mathrm{s}}$ is PS .

Near to points $c$ and $d$ the control behavior is similar to the point near a and $b$, respectively. Thus, some ideas can be summed up from the fuzzy rules of the fuzzy controller according to the value $\Delta \xi$ and the value $\gamma$ of $\delta_{\mathrm{s}}$ : when $\Delta \xi$ is bigger, we should take a larger stern rudder angle, in order to eliminate the depth deviation quickly, which is dominated by the depth deviation $\Delta \xi$ at this time in the controller. In terms of the size, such as preventing a larger overshoot, the stern rudder angle $\Delta \xi$ must be adequate, so as not to make a big overshoot. When $\Delta \xi$ is smaller and $\gamma$ is larger, the deviation is very small, and the main task is to prevent big overshoot or oscillation of the dominant, the stern rudder angle $\gamma$ must be the rudder. The timing of the compressive displacement at the helm must take an earlier action to process the slow and deep maneuvers during the dynamic process. Otherwise it will be too late to adjust the overshoot and the rudder angle. So this case will be based on the simulation debugging repeatedly to find the appropriate rules.

According to the depth of the submarine maneuvers of a typical step response, the fuzzy rule base on $\Delta \xi, \gamma$ and $\delta_{\mathrm{s}}$ can be obtained.

Table 1. The fuzzy rule base on $\Delta \xi, \gamma$ and $\delta_{s}$

\begin{tabular}{|c|c|c|c|c|c|}
\hline ds & NB & NS & ZE & PS & PB \\
\hline NB & PB & PM & PM & PS & ZE \\
\hline NS & PM & PS & PS & ZE & NS \\
\hline ZE & PS & ZE & ZE & NS & NM \\
\hline PS & PS & ZE & NS & NS & NM \\
\hline PB & NS & NM & NM & NM & NB \\
\hline
\end{tabular}

Using MATLAB fuzzy toolbox, we can see whether the designed fuzzy controller's performance is good or bad and use the toolkit to output each linguistic variable fuzzy inference characteristic of the curved surface, as shown in Fig. 7.

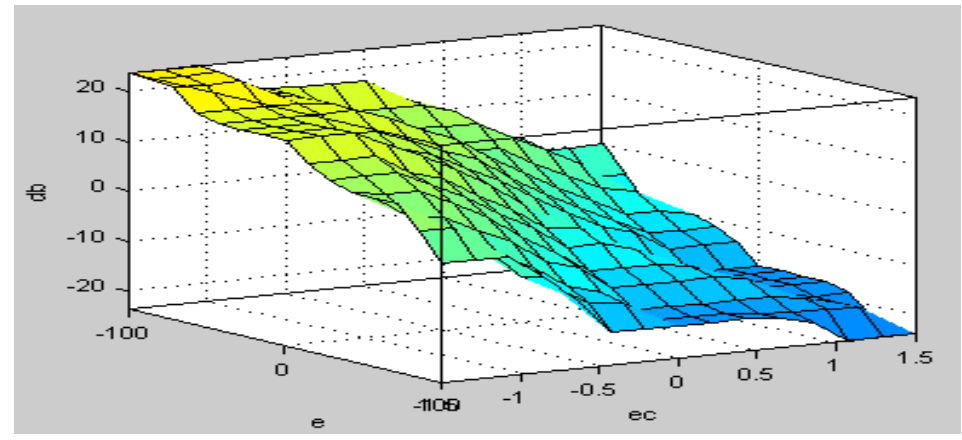

Fig. 7. $\Delta \xi$ and $\gamma$ fuzzy reasoning, output characteristic curved surface 
As it can be seen from Fig. 7, the fuzzy reasoning output characteristic shows surface smooth transition of $\Delta \xi, \gamma$ and $\delta_{\mathrm{s}}$, with no mutations. Therefore, the control system of the fuzzy control rules is reasonable.

\subsection{Fuzzy reasoning and solution of the fuzzy equation}

The fuzzy inference machine is the core of the fuzzy control system, according to the fuzzy input and fuzzy control rules. The fuzzy inference machine is to solve the fuzzy relation equation and obtain the fuzzy output.

The fuzzy inference machine is mainly used to control a system which has a product inference engine. In this paper we apply Mamdani minimum operation in the in-depth motor control system. The results obtained by the fuzzy inference machine are fuzzy, and for actual control the fuzzy quantity is not clear, so one needs to turn the fuzzy quantity into clear quantity. This is done in the theory of domain clear quantity within the scope of the scale transform into actual control. Fuzzy control computed their transformation within the scope of the clear quantity, accomplished via the solution of a fuzzy equation. This paper adopts the fuzzy center solution method, so that the output of a fuzzy controller is as follows:

$$
y^{*}=\sum_{i=1}^{M} \bar{y}^{l}\left(\prod_{i=1}^{n} \mu_{i}^{l}\left(x_{i}^{*}\right)\right) / \sum_{i=1}^{M}\left(\prod_{i=1}^{n} \mu_{i}^{l}\left(x_{i}^{*}\right)\right),
$$

where $y^{*}$ is the output of the stern rudder angle, and $\bar{y}^{l}$ is the center of the membership functions of the deviation depth $\Delta \xi$ and deviation rate of change. The central point in the membership function $\mu_{i}^{l}\left(x_{i}^{*}\right)$ is the membership function of the deviation depth $\Delta \xi$ and deviation rate of change $\gamma$.

\section{Trim of the fuzzy controller design}

\subsection{Theory and basic theory of domains}

Trim deviation theory $\Delta \theta=\theta_{z}-\theta$ domain here is $[-2,2]$, trim deviation rate $\kappa=d \Delta \theta / d t$ of the theory of domain for $[-1,1]$, and the control theory of stern rudder angle $\delta_{\mathrm{s}}$ domain is $[-6,6]$. According to the actual situation, choose the trim deviation control system of the basic theory of the domain as $[-10,10]$, trim the deviation rate of the basic theory of the domain as $[-1,1]$, the stern rudder angle of basic theory of the domain as $[-30,30]$.

\subsection{The quantization factor and scaling factor}

In deterministic theory and basic theory of domains, the quantization factor and scaling factor are determined as follows: 
(1) Trim deviation quantitative factors $K_{\mathrm{e} 2}=2 / 10=0.2$.

(2) The depth of the deviation rate of quantitative factors $K_{\text {ec2 }}=1$.

(3) The output scaling factor $K_{\mathrm{w} 2}=30 / 6=5$.

4.3. Fuzzy language variables and determination of the membership function

The input and output language variables of the fuzzy controller are set to seven, respectively $\{(\mathrm{NB}),(\mathrm{NM}),(\mathrm{NS}),(\mathrm{ZE}),(\mathrm{PS}),(\mathrm{PM}),(\mathrm{PB})\}$. According to the fuzzy language variables, we can get the deviation rate and stern rudder angle, then trim the membership function of the fuzzy subset as shown in Figs 8, 9 and 10.

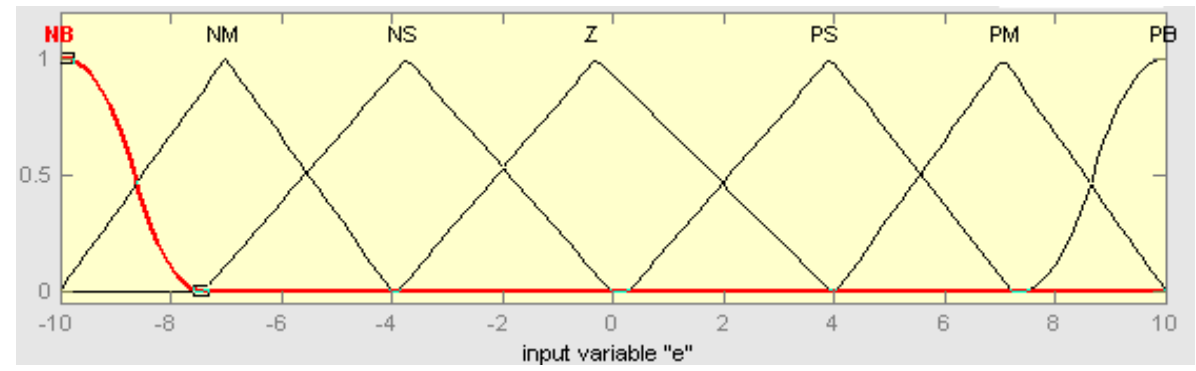

Fig. 8. Membership functions of trim deviation $\Delta \theta$

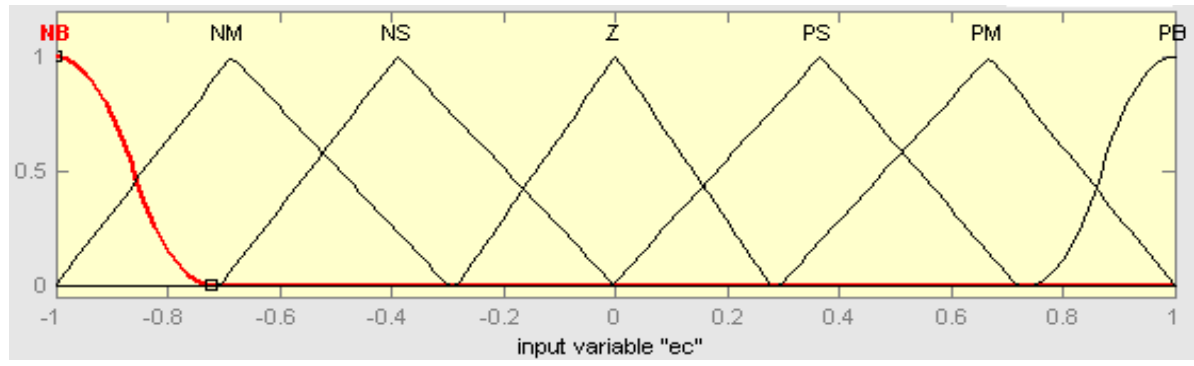

Fig. 9. Membership functions of trim deviation rate $\kappa$

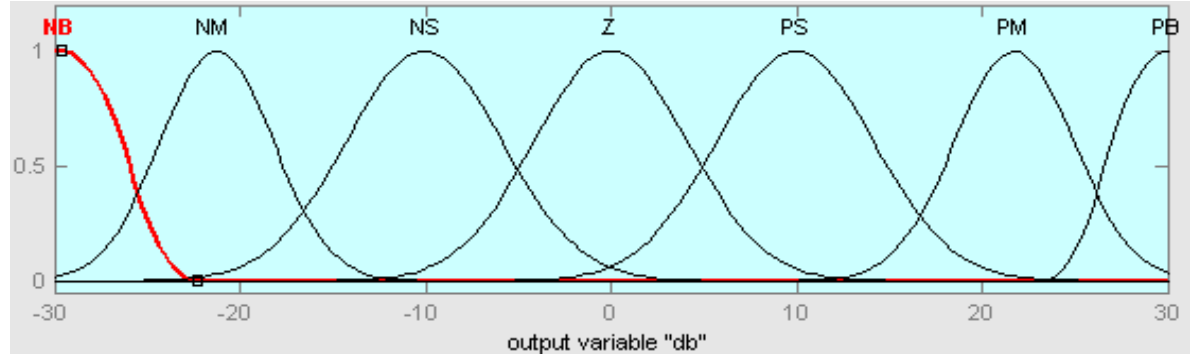

Fig. 10. Membership functions of the stern rudder angle $\delta$ s 


\subsection{Determination of the fuzzy rules}

According to the depth of the submarine maneuvers of a typical step response, $\Delta \theta$, $\kappa$ and $\delta_{\mathrm{s}}$ of the fuzzy rule base can be obtained; the rules are shown in Table 2.

Table 2. $\Delta \theta, \kappa$ and $\delta_{\mathrm{s}}$ of the fuzzy rule base

\begin{tabular}{|c|c|c|c|c|c|c|c|}
\hline ds & NB & NM & NS & ZE & PS & PM & PB \\
\hline NB & PB & PB & PM & PM & PS & PS & ZE \\
\hline NM & PB & PM & PM & PS & PS & ZE & ZE \\
\hline NS & PM & PM & PS & PS & ZE & NS & NS \\
\hline ZE & PS & PS & ZE & ZE & NS & NS & NM \\
\hline PS & PS & ZE & ZE & NS & NS & NM & NM \\
\hline PM & ZE & NS & NS & NM & NM & NM & NB \\
\hline PB & NS & NS & NM & NM & NM & NB & NB \\
\hline
\end{tabular}

Using MATLAB fuzzy toolbox, we can see each linguistic variable fuzzy inference characteristic of the curved surface, shown in Fig. 11.

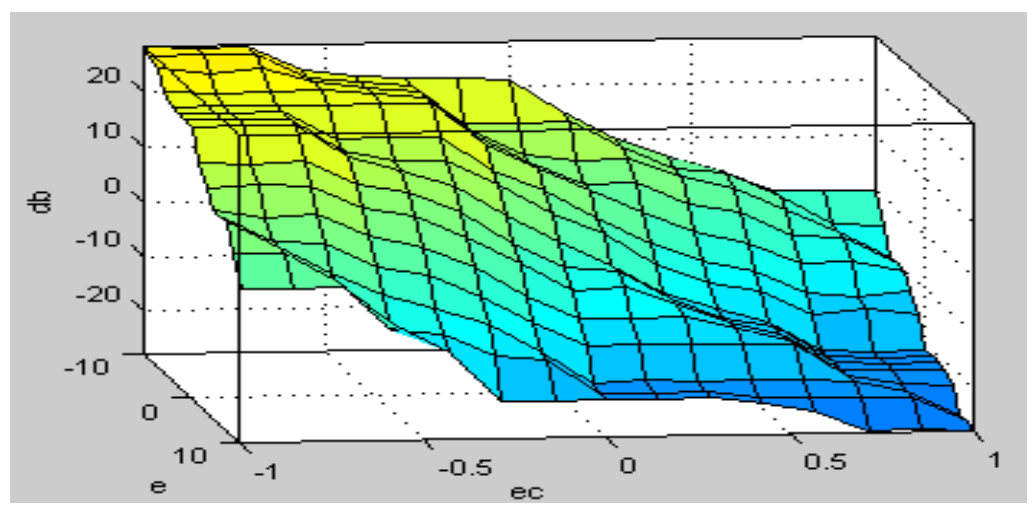

Fig. 11. $\Delta \theta, \kappa$ and $\delta_{\mathrm{s}}$ fuzzy reasoning, output characteristic curved surface

As it can be seen from Fig. 11, $\Delta \theta, \kappa$ and $\delta_{\mathrm{s}}$ of fuzzy reasoning, the output characteristic curved surface has smooth transition with no mutations. Accordingly, a trim controller of the fuzzy control rules is reasonable.

\subsection{Fuzzy reasoning and solution of the fuzzy method}

Trim controller also uses Mamdani minimum operations, methods of fuzzy center fuzzy solution, the output of the controller: solutions of the fuzzy method uses the fuzzy center solution, below is given the output of the controller:

$$
y^{*}=\sum_{i=1}^{M} \bar{y}^{l}\left(\prod_{i=1}^{n} \mu_{i}^{l}\left(x_{i}^{*}\right)\right) / \sum_{i=1}^{M}\left(\prod_{i=1}^{n} \mu_{i}^{l}\left(x_{i}^{*}\right)\right)
$$

Where $y^{*}$ is the output of the stern rudder angle; $\bar{y}^{l}$ is the center of the membership functions of the trim deviation $\Delta \theta$ and trim deviation rate $\kappa$; as the 
central point in the membership function, $\mu_{i}^{l}\left(x_{i}^{*}\right)$ are the membership functions of the trim deviation $\Delta \theta$ and trim deviation rate $\kappa$.

\section{System simulation}

In order to verify the control effect of the single stern rudder, in viewpoint of the submarine in water of infinite depth, width, static speed of $8 \mathrm{kn}$, hardware-in-theloop simulation is carried out for the motor depth.

(1) The initial depth is $60 \mathrm{~m}$, the target depth is $90 \mathrm{~m}$, instruction trim $2^{\circ}$, rudder speed $2.5^{\circ}$ per $1 \mathrm{~s}$, sampling time is $0.2 \mathrm{~s}$, simulation time is $600 \mathrm{~s}$. The simulation curve is shown in Figs 12 up to 14.

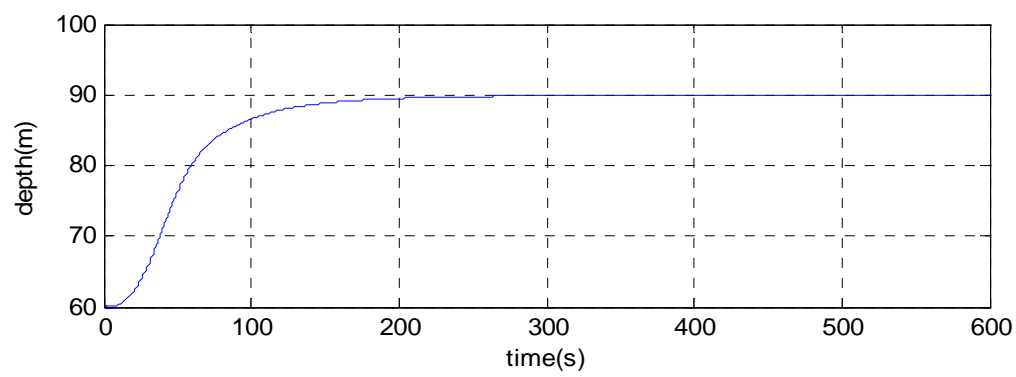

Fig. 12. The depth of the curve

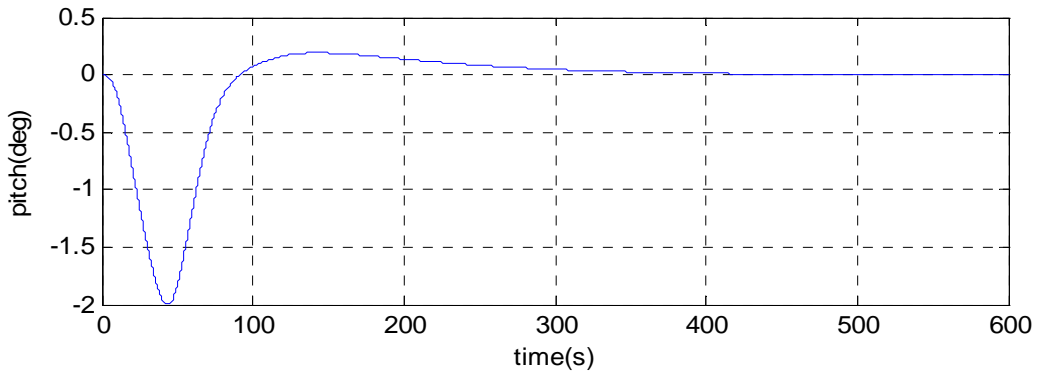

Fig. 13. Shell rudder angle, stern rudder angle change curve

As it can be seen from the simulation, at depth of no overshoot, the mobile time is $263 \mathrm{~s}$, there is no static difference after the steady state. By the trim curve we can see that at the beginning the motor depth in a trim controller is up to $2^{\circ}$ instructions trim; under the action of $44 \mathrm{~s}$ it reaches the directive trim, the depth of the controller starts to work at this time, the depth is $73.2 \mathrm{~m}$, according to the current depth the depth of the deviation, the final depth of stability in $90 \mathrm{~m}$ depth are controlled. In the whole process of the motor shell, the rudder angle is always zero, the stern rudder is steering four times. Smooth and no oscillation phenomenon is noticed in the transition process. Therefore, we adopt the single stern rudder control in the motor process, the twin rudder significantly reduces the steering input, so we can further reduce the radiated noise of a submarine in low noise condition. The noise to further reducing of the input of the biggest rudder angle will 
restrict the stern rudder, the maximum angle of the stern rudder being $8^{\circ}$, the rudder speed $-2.5^{\circ}$ per $1 \mathrm{~s}$.

(2) The speed is $6 \mathrm{Kn}$, the initial depth is $60 \mathrm{~m}$, the target depth is $90 \mathrm{~m}$, the instruction of trim is $1.5^{\circ}$, the stern rudder angle is the biggest one $-10^{\circ}$, the sampling time is $0.2 \mathrm{~s}$, the simulation time is $800 \mathrm{~s}$.

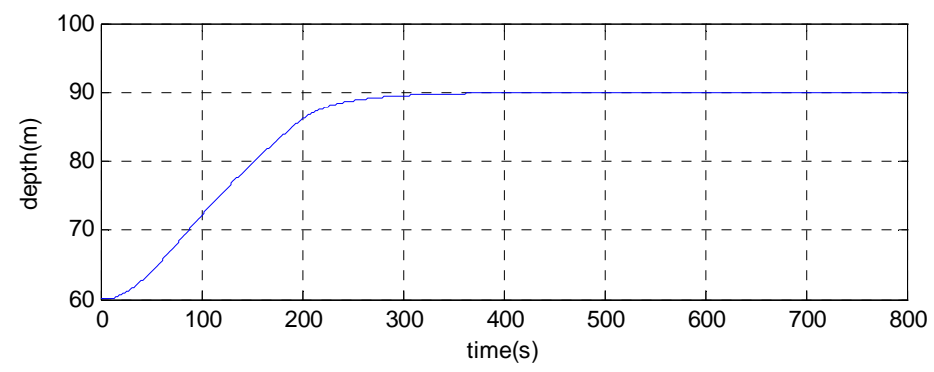

Fig. 14. The depth of the curve

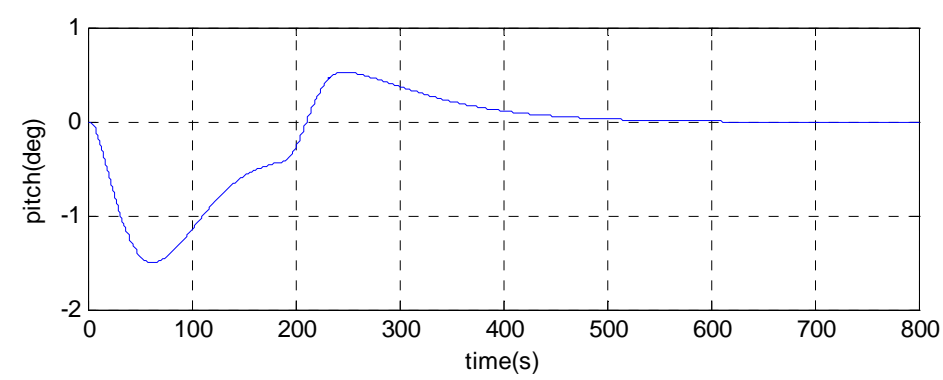

Fig. 15. The curves of trim

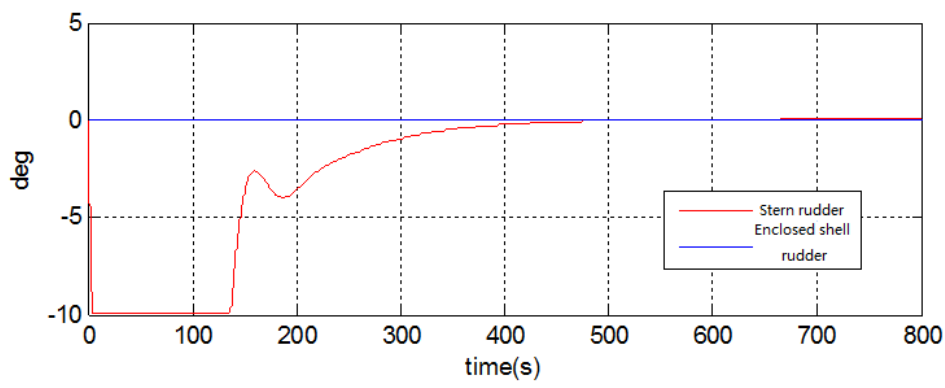

Fig. 16. Shell rudder angle, stern rudder angle change curve

From Figs 14 up to 16 we can see that under the condition that the limit of the rudder depth is still not overshoot, the trim angle after reaching a directive trim angle of $1.5^{\circ}$, under the action of the righting moment stabilizes to zero. But in the case of a low speed, the time of a single stern rudder maneuver is long, in $6 \mathrm{Kn}$ depth correction under speed of $30 \mathrm{~m}$, the maneuvering time is nearly $300 \mathrm{~s}$, adverse to the rapid mobility, but in order to reduce the noise under the appropriate sacrifice mobility, it is worth. 


\section{Conclusion}

In this paper we use a single stern rudder fuzzy controller to obtain the vertical and trim control of a submarine in deep water. The simulation results show that the submarine trim changes a little, and a small amount of the rudder shows that the controller has a good control effect, the input of the submarine can greatly reduce the noise and radiation noise.

Acknowledgements: We would like to thank to the Foundation of the Fundamental Research Funds for the Central Universities, South-Central University for Nationalities (CZY14002), the Foundation of Hubei Key Laboratory of Intelligent Wireless Communications, the South-Central University for Nationalities, China.

\section{References}

1. A n on. Wonderware and Woodhead Strengthen Connectivity with ArchestrA Technology. Paper Industry, Vol. 21, 2004, Issue 6, pp. 15-17.

2. F ang, W a n-S hu i, W e i Li, J in g-B i a o C a i. The Generalization of Integrated Platform Management System's Development for Foreign Naval Ships. - Ship Science and Technology, Vol. 27, 2005, Issue 1, pp. 94-96.

3. L i n, J i a n-H u i, S o n g-T a o C h e n. Integrated Platform Management System for Ships Based on Industrial Ethernet. - Jiangsu Ship, Vol. 29, 2012, Issue 2, pp. 31-35.

4. Re n, Y u e-Q i n, Hu i X u. Development of Integrated Platform Management System. - Ship Science and Technology, Vol. 27, 2005, Issue 6, pp. 105-108.

5. H a n, Q i, R u-Q u a n M a o. Network Pattern of Naval Ship Synthesized Platform Management. - Ship \& Boat, Vol. 8, 2004, Issue 4, pp. 56-58.

6. Y e, Y in g, J u n-H u a L i. Research of Integrated Platform Management System For Ships. China Water Transport, Vol. 4, 2006, Issue 11, pp. 15-16.

7. Huang, Long-Shui, Yun-Biao Sun. Architecture of Warship Integrated Platform Management System. - Ship Electronic Engineering, Vol. 24, 2004, Issue 6, pp. 50-54.

8. W e i, S o n g, Y in g X i o n g, P e n g $\mathrm{H}$ u. Establishment of Universal Model of Ship Integrated Platform Management System. - Chinese Journal of Ship Research, Vol. 3, 2008, Issue 5, pp. 57-61.

9. P a p o u li a s, F. A., B. D. M c k i n l e y. Inverted Pendulum Stabilization of Submarines in Free Positive Buoyancy Ascent. - J. S. R., Vol. 38,1994, Issue 1, pp. 71-82.

10. R i chard s, R. J., C. P. S t o t e n. Depth Control of a Submersible Vehicles. - I.S.P., Vol. 28, 1981, Issue 318, pp. 30-39.

11. G u e l e r, G. F. Modelling Design and Analysis of an Autopilot for Submarine Vehicles. - I.S.P., Vol. 36, 1989, Issue 405, pp. 51-58. 